EDUARDO DE SOUZA²

Patrícia Coelho de Soárez ${ }^{3}$

adauto Castelo Fllho ${ }^{4}$

Abês MAHMEd AMED ${ }^{2}$

\title{
Qualidade de vida de gestantes infectadas pelo vírus da imunodeficiência humana (HIV) na cidade de São Paulo
}

\author{
Quality of life of pregnant women infected with the buman \\ immunodeficiency virus (HIV) in the city of São Paulo
}

Artigo Original

\author{
Palavras-chave \\ Qualidade de vida \\ Gestantes \\ HIV \\ Cuidado pré-natal \\ Questionários \\ Keywords \\ Quality of life \\ Pregnant women \\ HIV \\ Prenatal care \\ Questionnaires
}

\section{Resumo}

OBJETIVO: Avaliar a qualidade de vida (QV) de gestantes infectadas pelo HIV, utilizando o questionário HIV/ AIDS - Targeted Quality of Life (HAT-QoL). MÉTODOS: Estudo descritivo que incluiu 60 gestantes atendidas no Núcleo Multidisciplinar de Patologias Infecciosas na Gestação (NUPAIG) - UNIFESP/EPM e na rede de referência da Secretaria Municipal de São Paulo. Foi realizado no período de fevereiro de 2011 a outubro de 2012 . Foram coletadas variáveis sociodemográficas e clínicas de 60 gestantes infectadas pelo HIV, que responderam o questionário HAT-QoL, o qual incluiu 34 questões sobre qualidade de vida. RESULTADOS: A média de idade foi 30 anos e o tempo médio de infecção pelo HIV foi de 5,7 anos. Somente 8,3\% das pacientes tinham contagem de células CD4 $\leq 200$ células $\mathrm{mm}^{3}$ e $45 \%$ apresentavam carga viral indetectável. Os escores médios dos domínios variaram entre 47,5 e 83,7. Os domínios com escores mais baixos foram preocupações financeiras e preocupações com o sigilo. Os domínios com escores mais altos e menor impacto na qualidade de vida foram preocupações com a medicação e confiança no profissional. CONCLUSÃO: Neste estudo inicial, com 60 grávidas, concluímos que o HAT-QOL poderá contribuir para a avaliação da qualidade de vida na população de gestantes infectadas pelo HIV no Brasil.

Abstract

PURPOSE: It was to assess the quality of life (QOL) of HIV-infected pregnant women using the HIV/AIDS - Targeted Quality of Life (HAT-QoL) questionnaire. METHODS: A descriptive study of 60 pregnant women attended at the Multidisciplinary Nucleus of Infectious Diseases During Pregnancy (NUPAIG) - UNIFESP/EPM and in the referral network of the Municipal Office of São Paulo, conducted from February 2011 to October 2012. Sociodemographic and clinical variables were collected from $60 \mathrm{HIV}$-infected pregnant women who answered the HAT-QoL questionnaire, which included 34 questions about quality of life. RESULTS: The average age was 30 years and the average period of HIV infection was 5.7 years. Only $8.3 \%$ of patients had a CD4 cell score of $\leq 200$ cells $/ \mathrm{mm}^{3}$ and $45 \%$ showed undetectable viral load. The average domain scores ranged from 47.5 to 83.7. The domains with the lowest scores were financial concerns and concerns about secrecy. The domains with the highest scores and lower impact on quality of life were concerns about medication and confidence in the professional. CONCLUSION: In this initial study with 60 pregnant women, we concluded that the HAT-QOL can contribute to the assessment of quality of life in the population of HIV-infected pregnant women in Brazil.
Correspondência Rua Napoleão de Barros, 875 - Vila Clementino CEP: 04024-002

São Paulo (SP), Brasil

Recebido

$16 / 01 / 2014$

Aceito com modificaçōes

$17 / 04 / 2014$
Departamento de Obstetrícia da Escola Paulista de Medicina da Universidade Federal de São Paulo - UNIFESP - São Paulo (SP), Brasil. IPrograma de Pós-Graduação em Obstetrícia, Escola Paulista de Medicina, Universidade Federal de São Paulo - UNIFESP São Paulo (SP), Brasil.

2Departamento de Obstetrícia, Escola Paulisła de Medicina, Universidade Federal de São Paulo - UNIFESP - São Paulo (SP), Brasil. ${ }^{3}$ Departamento de Medicina Preventiva, Faculdade de Medicina, Universidade de São Paulo - USP - São Paulo (SP), Brasil.

${ }^{4}$ Departamento de Infectologia, Escola Paulista de Medicina, Universidade Federal de São Paulo - UNIFESP - São Paulo (SP), Brasil. Conflito de interesses: não há. 


\section{Introdução}

$\mathrm{O}$ advento de medicamentos cada vez mais potentes, desenvolvidos na tentativa de reverter a imunoincompetência causada pelo HIV-1 aos indivíduos infectados pelo HIV, oferece, na atualidade, maior sobrevida e melhor qualidade de vida para o paciente, o que foi um grande avanço para essa população ${ }^{1}$.

No entanto, ainda é crescente a preocupação com as estratégias de enfrentamento da epidemia mundialmente ${ }^{2}$. Nesse contexto, foram notificados no município de São Paulo, de janeiro de 2000 a junho de 2012, 6.107 casos de gestantes com HIV positivo, dos quais a realização de pré-natal manteve-se acima de $93 \%$. Além disso, houve uma melhora acentuada no desempenho dos medicamentos antirretrovirais nesse período, e a porcentagem das gestantes infectadas pelo vírus que fizeram uso desses fármacos chegou a $89,6 \%$ em $2012^{3}$.

As gestantes com HIV positivo devem ser acompanhadas visando a cobrir diferentes necessidades do ciclo gravídico puerperal, contando com atuação conjunta de equipe multiprofissional (médicos ginecologistas e obstetras, infectologistas, enfermeiros, psicólogos, nutricionistas e assistentes sociais), o que dará à paciente melhor qualidade de vida e, consequentemente, diminuirá a morbidade e mortalidade do binômio mãe-concepto ${ }^{4}$.

A compreensão da qualidade de vida das pessoas que vivem com o HIV/AIDS é fundamental, considerando a cronicidade da infecção, o tratamento, a maior sobrevida e o aspecto estigmatizante da doença, conforme trabalho desenvolvido em dois ambulatórios da rede SUS do interior de São Paulo com mulheres 5 .

Segundo a Organização Mundial de Saúde (OMS), qualidade de vida envolve o bem-estar físico, mental, psicológico e emocional do indivíduo ${ }^{6}$. Contudo, não é fácil aferi-la.

Entre vários instrumentos, optamos por utilizar o questionário de qualidade de vida direcionado para HIV/ AIDS, traduzido, adaptado e validado para pacientes HIV no Brasil HAT-QoL ${ }^{7}$.

O objetivo desse trabalho foi avaliar a qualidade de vida de gestantes infectadas pelo HIV atendidas em centros de referência para esse tipo de intercorrência no município de São Paulo.

\section{Métodos}

Trata-se de um estudo descritivo que incluiu gestantes infectadas pelo HIV atendidas no Núcleo Multidisciplinar de Patologias Infecciosas na Gestação (NUPAIG) da Universidade Federal de São Paulo e na rede de referência da Secretaria Municipal da Saúde de São Paulo. O levantamento foi realizado no período de fevereiro de 2011 a outubro de 2012.

A população do estudo era uma amostra de conveniência composta por gestantes infectadas pelo HIV, após passarem pela admissão do pré-natal e fazerem a primeira contagem de células CD4 + e quantificação da carga viral. Foram excluídas as analfabetas, menores de idade, pacientes comprovadamente psiquiátricas e gestantes vivendo com privação de liberdade.

A coleta de dados foi realizada em sala privativa dos ambulatórios, o que permitiu sigilo. Para melhor caracterização da população, foram estabelecidas as seguintes variáveis sociodemográficas: idade, estado civil, raça, grau de instrução, profissão, renda familiar e hábitos de vida (tabagismo, etilismo e consumo de drogas), bem como dados clínicos: CD4 $\left(\mathrm{mm}^{3}\right)$ e carga viral.

No mesmo encontro, na forma de entrevista, foi aplicado o instrumento HIV/AIDS - Targeted Quality of Life (HAT-QoL) ${ }^{7}$, específico para avaliação de qualidade de vida em pacientes infectados pelo HIV. O HAT-QoL foi adaptado culturalmente e teve as propriedades psicométricas da versão em português do Brasil avaliadas. É compreensível e de fácil aplicação, tendo apresentado boa validade de construto e excelente confiabilidade. É composto por 34 itens, divididos em nove domínios (função geral, contentamento com a vida, preocupações com a saúde, preocupações financeiras, preocupações com a medicação, aceitação do HIV, preocupações com o sigilo, confiança no profissional e função sexual). Para responder a cada item, as grávidas eram conduzidas a refletir sobre sua qualidade de vida nas últimas quatro semanas. As respostas têm formato de escala do tipo Likert de cinco pontos ("todo o tempo", "a maior parte do tempo", "parte do tempo", "pouco tempo" e "nunca").

Em cada domínio, zero era o menor escore possível e cem o maior. Quanto maior o escore, menor o impacto da infecção pelo HIV sobre a qualidade de vida da gestante; ao contrário, quanto menor o escore, mais comprometida se encontrava a paciente no que se refere a cada um dos domínios relacionados anteriormente.

Para a análise, os dados foram organizados em planilha Excel, com dupla digitação, para evitar erros de transcrição. Os dados foram tabulados e transferidos para o software estatístico Minitab, versão 16.0.

Para as variáveis de natureza quantitativa (numérica), foram calculadas algumas medidas-resumo, como média, mediana, valor mínimo, valor máximo e desvio padrão; para as variáveis categóricas, foram usados números absolutos e relativos (n e \%). Em conformidade com 
as variáveis sociodemográficas e clínicas, fizemos uma exposição descritiva.

Este estudo foi aprovado pelo Comitê de Ética Institucional da Escola Paulista de Medicina da Universidade Federal de São Paulo em 24 de setembro de 2010 (1358/10) e pela Secretaria Municipal de Saúde (Comitê de Ética em Pesquisa), conforme parecer 026/12 - CEP/SMS de 7 de fevereiro de 2012.

\section{Resultados}

Os resultados foram estabelecidos a partir de um total de 60 gestantes infectadas pelo HIV. No serviço do NUPAIG, quatro pacientes foram excluídas (um parto prematuro sem resultado de CD4 e carga viral nas últimas quatro semanas, dois casos de aborto espontâneo também sem tipagem recente e um caso psiquiátrico). Nos centros de referência da rede municipal da cidade de São Paulo, apenas um caso foi excluído (paciente presidiária).

A idade das gestantes variou de 18 a 45 anos, com média de 30 anos. A idade gestacional das pacientes apresentou média de 26 semanas. O tempo médio de infecção pelo vírus foi de 68,3 meses (5,7 anos) - no mínimo 2 e no máximo 252 meses. Somente 2 haviam contraído o vírus por transmissão vertical; 44 já tinham conhecimento da infecção pelo HIV antes daquela gestação. Da amostra, apenas 8,3\% apresentaram $\mathrm{CD} 4 \leq 200 \mathrm{~mm}^{3}$. Quanto à carga viral, foi avaliada entre detectável (33 casos) e indetectável (27). Apenas 7 gestantes não estavam sob uso do antirretroviral para HIV positivo; 48 gestantes utilizaram esse medicamento nos dois meses anteriores.

Além desses dados, duas tabelas foram confeccionadas. A Tabela 1 apresenta alguns dados sociodemográficos e clínicos para caracterização da população. A Tabela 2 apresenta a descrição dos escores de cada domínio do HAT-QoL.
Tabela 1. Dados sociodemográficos e clínicos das 60 gestantes infectadas pelo HIV

\begin{tabular}{|c|c|c|c|}
\hline Variáveis & & n & $\%$ \\
\hline \multirow{2}{*}{ Estado civil } & Solteiras, separadas e viúvas & 22 & 36,7 \\
\hline & Casadas, união de fato e união estável & 38 & 63,3 \\
\hline \multirow{2}{*}{ Raça } & Branca & 21 & 35,0 \\
\hline & Parda e afrodescendente & 49 & 65,0 \\
\hline \multirow{2}{*}{$\begin{array}{l}\text { Grau de } \\
\text { instrução }\end{array}$} & Até a nona série & 17 & 28,3 \\
\hline & Ensino médio incompleto a superior completo & 43 & 71,7 \\
\hline \multirow{2}{*}{ Profissão } & Registrada ou autônoma & 27 & 45,0 \\
\hline & Do lar ou desempregada & 33 & 55,0 \\
\hline \multirow{3}{*}{$\begin{array}{l}\text { Renda/ } \\
\text { salário familiar }\end{array}$} & De meio salário mínimo a dois salários mínimos e meio & 23 & 38,3 \\
\hline & Acima de dois salários mínimos e meio & 13 & 21,7 \\
\hline & Sem nenhuma renda/não declarado & 24 & 40,0 \\
\hline Tabagismo & & 12 & 20,0 \\
\hline Etilismo & & 02 & 3,3 \\
\hline Drogas ilícitas & & 07 & 11,7 \\
\hline \multirow{4}{*}{$\mathrm{CD} 4\left(\mathrm{~mm}^{3}\right)$} & $\leq 200$ & 05 & 8,3 \\
\hline & $>200$ a 350 & 19 & 31,7 \\
\hline & $>350$ a 500 & 10 & 16,7 \\
\hline & $>500$ & 26 & 43,3 \\
\hline \multirow{2}{*}{ Carga viral } & Detectável & 33 & 55,0 \\
\hline & Indetectável & 27 & 45,0 \\
\hline
\end{tabular}

\section{Discussão}

$\mathrm{Na}$ nossa revisão internacional de literatura, não encontramos trabalhos com gestantes para as quais tenha sido usado o HAT-QoL, portanto nos restringimos a citar apenas dois estudos, que utilizaram outros instrumentos. Esses trabalhos foram desenvolvidos com grávidas em Portugal e na África do Sull ${ }^{8,9}$, países onde, apesar das diferenças intercontinentais, as grávidas infectadas pelo HIV mantinham menores escores de qualidade de vida perante as soronegativas.

O questionário HAT-QoL, desenvolvido por Holmes e Shea ${ }^{10}$ e traduzido por De Soárez et al. ${ }^{7}$ para o português, adaptado culturalmente e avaliado em suas propriedades

Tabela 2. Escores dos domínios do HIV/Aids - Targeted Quality of Life

\begin{tabular}{|c|c|c|c|c|c|c|}
\hline Domínios & $n$ & Média & Desvio padrão & Mínimo & Mediana & Máximo \\
\hline DOM1 - Função geral & 60 & 68,8 & 18,3 & 8,3 & 75,0 & 100,0 \\
\hline DOM2 - Contentamento com a vida & 60 & 67,4 & 24,5 & 18,7 & 68,7 & 100,0 \\
\hline D0M4 - Preocupações financeiras & 60 & 49,4 & 31,5 & 0,0 & 50,0 & 100,0 \\
\hline DOM5 - Preocupações com medicação & 53 & 83,1 & 19,5 & 15,0 & 85,0 & 100,0 \\
\hline DOM6 - Aceitação do HIV & 60 & 68,0 & 35,4 & 0,0 & 75,0 & 100,0 \\
\hline DOM8 - Confiança profissional & 60 & 83,7 & 20,4 & 8,3 & 87,5 & 100,0 \\
\hline DOM9 - Funcão sexual & 60 & 65,4 & 35,5 & 0,0 & 75,0 & 100,0 \\
\hline
\end{tabular}

Nota: escore máximo =100,0 para todos os domínios 
psicométricas (validade e confiabilidade) em pacientes infectadas pelo HIV, se mostrou o mais adequado para as gestantes dessa amostra, por ser destinado especificamente a essa população e também porque a literatura internacional é escassa quanto a grávidas HIV positivo que tenham utilizado tal questionário. Faltava assim um instrumento de atuação clínica que pudesse fundamentar essa assistência na realidade da cidade de São Paulo em centros de referência.

No que tange aos nove domínios do HAT-Qol, os mais comprometidos foram os de preocupações com o sigilo e financeiras, o que coincide com a análise bibliográfica sobre indivíduos (não gestantes) portadores do vírus em alguns trabalhos no Brasil ${ }^{10-12}$. Ainda assim, esses escores estão um pouco abaixo de 50 , não sendo tão ruins quando comparados aos de pacientes sul-africanas ${ }^{13}$.

Com referência ao domínio função sexual, não podemos afirmar que as gestantes tenham refletido ao responder sobre esse aspecto, que terá que ser mais pesquisado. Segundo alguns autores, a sexualidade é um fenômeno de grande significado existencial. Seu padrão de normalidade ou anormalidade sofre muita influência dos valores socioculturais. A imagem do mal associado à infecção pelo HIV faz com que a sexualidade possa ser vista como anormal. Com o advento da terapia antirretroviral, houve um estímulo à sexualidade normal, o que poderia justificar o escore encontrado nessa pesquisa ${ }^{14}$.

Outro domínio a ser destacado é o de contentamento com a vida, no qual o escore para qualidade de vida (67) corresponde a quanto a gestante está no controle de sua vida (satisfeita por estar saudável, com bom nível de atividades sociais). A satisfação na vida pode estar relacionada ao coping (enfrentamento da doença). Alguns autores que discorreram sobre esse aspecto referem bons resultados na qualidade de vida de 107 homens em clínicas especializadas em HIV/AIDS em Toronto (Canadá). Estes, em sua maioria, apresentaram apoio social positivo e bons recursos para enfrentamento da doença ${ }^{15}$. Em pesquisa nacional ${ }^{12}$, o índice encontrado para o gênero feminino foi próximo ao nosso.

Quanto ao domínio aceitação do HIV, a pesquisa corrobora trabalho nacional ${ }^{12}$, somado ao fato de que acirradas campanhas governamentais vêm há anos divulgando e promovendo o conhecimento do vírus, com diretrizes claras preconizadas pelo Ministério da Saúde, incluindo aconselhamento para essa população em praticamente todas as redes HIV/AIDS ${ }^{16}$. Diante desse quadro, não nos surpreendeu que tal dimensão obtivesse escore alto para qualidade de vida.

Com referência ao domínio função geral (percepção de dor e atividades gerais), perto de $70 \%$ da população evidenciou marcador de boa qualidade de vida. Contudo, é importante lembrar que as pesquisadas tinham por volta de 26 semanas de gravidez, período em que a mulher tende a se adaptar melhor à gestação, o que pode ter interferido na resposta. Nesse momento a grávida já está mais familiarizada com o estado gravídico e seus sinais peculiares ${ }^{17}$ (enjoos, cefaleia, modificações da psique, hipersensibilidade das mamas, etc.); alguns desses sintomas estão inclusive mais estáveis. Sem contar com os benefícios de uma assistência de pré-natal mais especializada, na qual se prioriza a manutenção da saúde materna na melhor condição possível e a consequente redução da taxa de transmissão vertical ${ }^{18}$.

Já o domínio relativo às preocupações com a saúde pode estar relacionado à especialização dos serviços de atendimento de pré-natal ${ }^{18}$ e ainda ao próprio fato de a gestante preocupar-se com a criança que vai nascer, o que foi perceptível no contato com as grávidas dessa amostra. Tais dados estão em consonância com pesquisa de adesão de gestantes com HIV/AIDS à terapia antirretroviral, que discorre sobre o medo das mães de passarem o vírus ao filho, o que impulsiona essa mulher a se cuidar e a aderir ao tratamento ${ }^{19}$. Trabalho recente sobre apego materno fetal em gestante que vive com HIV/AIDS não encontrou diferenças significativas entre grávidas infectadas pelo vírus e soronegativas quanto ao escore total de apego materno fetal. Tais evidências, com base nesses resultados, pressupõem que a presença do vírus não afetaria a capacidade da gestante de se vincular à criança que está para nascer ${ }^{20}$.

O escore médio do domínio confiança no profissional demonstrou uma relação saudável no binômio médico-paciente, pois interferiu positivamente na qualidade de vida. A relação que a mulher grávida tem com seus cuidadores de saúde, notoriamente os médicos, pode afetar as decisões que ela toma sobre o atendimento no pré-natal e a consequente adesão medicamentosa na prevenção da transmissão do HIV ao filho ${ }^{21}$.

O segundo maior escore médio foi para o domínio das preocupações com a medicação, muito próximo do anterior. Conforme já mencionado, o advento dos medicamentos para o HIV mudou o panorama da doença ${ }^{1}$. Uma revisão sobre a adesão à terapia antirretroviral em adultos com HIV/AIDS demonstrou que, entre 40 produções científicas com esse enfoque, $72,5 \%$ foram originárias da área da Medicina, seguida de Enfermagem (15\%), Psicologia (3\%) e Farmácia (2\%), no período de 2002 a 2011. O Brasil apresentou à época seis pesquisas, ficando atrás apenas dos EUA e da Inglaterra, o que reforça a importância desse tipo de política pública e de bem-estar, que encontra consonância com o resultado satisfatório no domínio (supramencionado ${ }^{22}$.

Pode-se inferir com o nosso estudo que a qualidade de vida das gestantes infectadas pelo HIV atendidas nos centros de referência citados apresentou-se de regular para boa. O HAT-QoL pode contribuir para a avaliação da qualidade de vida na população de gestantes infectadas pelo HIV, apesar de este ser um estudo inicial e não ter abarcado outros serviços públicos e privados, o que poderá ser averiguado por meio de outros trabalhos. Sugere-se que estudos sejam realizados com uma amostragem superior de grávidas, incluindo outras redes de saúde. 
1. Samuel R, Bettiker R, Suh B. Antiretroviral therapy 2006: pharmacology, applications, and special situations. Arch Pharm Res. 2006;29(6):431-58.

2. Joint United Nations Programme on HIV/AIDS (UNAIDS). Global report: UNAIDS report on the global AIDS epidemic 2013. Geneva: WHO; 2013.

3. Transmissão vertical do HIV. Bol Epidemiol AIDS/DST e Hepatites B e C do Município de São Paulo [Internet]. 2012;15(16):52-4 [citado 2013 Out 1 1]. Disponível em: http://www10.prefeitura. sp.gov.br/dstaids/novo_site/images/fotos/boletim2012.pdf

4. Lindsey PC, Amed AM. Acompanhamento da mulher HIV positivo no ciclo gravídico puerperal. In: Bortoletti FF, Moron AF, Bortoletti Filho J, Nakamura UM, Santana RM, Mattar R. Psicologia na prática obstétrica: abordagem interdisciplinar. Barueri: Manole; 2007. p. 289-90.

5. Gaspar J, Reis RK, Pereira FMV, Neves LAS, Castrighini CC, Gir E. Qualidade de vida de mulheres vivendo com HIV/Aids de um município do interior de paulista. Rev Esc Enferm USP. $2011 ; 45(1): 230-6$.

6. World Health Organization. Constitution. Geneva: WHO; 1946.

7. De Soárez PC, Castelo A, Abrão P, Holmes WC, Ciconelli RM. Tradução e validação de um questionário de avaliação de qualidade de vida em AIDS no Brasil. Rev Panam Salud Pública. 2009;25(1):69-76.

8. Nuwagaba-Biribonwoha H, Mayon-White RT, Okong P, Carpenter $L M$, Jenkinson $C$. The impact of HIV on maternal quality of life in Uganda. AIDS Care. 2006;18(6):614-20.

9. Pereira $M$, Canavarro MC. Quality of life and emotional distress among HIV-positive women during transition to motherhood. Span J Psychol. 2012;15(3):1303-14.

10. Holmes WC, Shea JA. Performance of a new, HIV/AIDS-targeted quality of life (HAT-QoL) instrument in asymptomatic seropositive individuals. Qual Life Res. 1997;6(6):561-71.

11. Galvão MTG, Cerqueira ATAR, Machado-Marcondes J. Avaliação da qualidade de vida de mulheres com HIV/AIDS através do HAT-QoL. Cad Saúde Pública. 2004;20(2):430-7.

12. Reis RK, Santos CB, Dantas RAS, Gir E. Qualidade de vida, aspectos sociodemográficos e de sexualidade de pessoas vivendo com HIV/AIDS. Texto Contexto Enferm. 2011 ;20(3):565-75.
13. Makin JD, Forsyth BW, Visser M, Sikkema KJ, Neufeld S, Jeffery B. Factors affecting disclosure in South African HIV-positive pregnant women. AIDS Patient Care STDS. 2008;22(11):907-16.

14. Souto BGA, Kiyota LS, Bataline MP, Borges MF, Korkischko N, Carvalho $S B B$, et al. $O$ sexo e a sexualidade em portadores do vírus da imunodeficiência humana. Rev Bras Clin Méd. 2009;7(3):188-91.

15. Friedland J, Renwick R, McColl M. Coping and social support as determinants of quality of life in HIV/AIDS. AIDS Care. 1996;8(1):15-31.

16. Brasil. Ministério da Saúde. Secretaria de Vigilância em Saúde. Programa Nacional de DST e AIDS [Internet]. Recomendações para profilaxia da transmisão vertical do HIV e terapia antirretroviral em gestantes: manual de bolso. Brasília (DF): Ministério da Saúde; 2010 [citado 2013 Out 13]. Disponível em: <http://www.aids. gov.br/sites/default/files/consenso_gestantes_2010_vf.pdf>

17. Tedesco JJA. A grávida: suas indagações e as dúvidas do obstetra. São Paulo: Atheneu; 1999.

18. Lindsey PC, Amed AM. Acompanhamento da grávida HIV+. In: Camano L, Souza E, Sass N, Mattar R. Obstetrícia. Barueri: Manole; 2003. p. 593-9. (Guias de Medicina ambulatorial e hospitalar, UNIFESP/Escola Paulista de Medicina).

19. Barros VL, Araújo MAL, Alcântara MNA, Guanabara MAO, Melo SP, Guedes SSS. Fatores que interferem na adesão de gestantes com HIV/AIDS à terapia antirretroviral. Rev Bras Promoç Saúde. $2011 ; 24(4): 396-403$.

20. Faria ER, Gonçalves TR, Carvalho FT, Ruschel PP, Lopes RCS, Piccinini CA. Apego Materno Fetal em gestantes que vivem com HIV/AIDS. Estud Psicol (Natal). 2013;18(2):231-9.

21. Barry OM, Bergh AM, Makin JD, Etsane E, Kershaw TS, Forsyth BW. Development of a measure of the patient-provider relationship in antenatal care and its importance in PMTCT. AIDS Care. 2012;24(6):680-6.

22. Zuge SS, Padoin SMM, Brum CN, Paula CC, Magnago TSBS, Santos EEP. Adhesión a la terapia antirretroviral en adultos con $\mathrm{VIH} / \mathrm{SIDA}$ : la naturaleza y la evolución de la producción científica. Enferm Comunitária [Internet]. 2012;8(2) [citado 2014 Abr 14]. Disponible en: http://www.index-f.com/comunitaria/v8n2/ ec8032e.php 